\title{
Considerations for Screening Live Kidney Donors for Endemic Infections: A Viewpoint on the UNOS Policy
}

\author{
M. E. Levi ${ }^{1, *}$, D. Kumar ${ }^{2}$, M. Green ${ }^{3}$, \\ M. G. Ison ${ }^{4,5}$, D. Kaul ${ }^{6}$, M. G. Michaels ${ }^{3}$, \\ M. I. Morris ${ }^{7}$, B. S. Schwartz ${ }^{8}$, I. A. Echenique ${ }^{4,5}$ \\ and $E$. A. Blumberg ${ }^{9}$ on behalf of the AST ID \\ Community of Practice \\ ${ }^{1}$ Division of Infectious Diseases, Department of \\ Medicine, University of Colorado, Denver, CO \\ ${ }^{2}$ Multi-Organ Transplant Program, University Health \\ Network, Toronto, ON, Canada \\ ${ }^{3}$ Children's Hospital of Pittsburgh of UPMC, Pittsburgh, \\ PA \\ ${ }^{4}$ Division of Infectious Diseases, Feinberg School of \\ Medicine, Northwestern University, Chicago, IL \\ ${ }^{5}$ Division of Organ Transplantation, Feinberg School of \\ Medicine, Northwestern University, Chicago, IL \\ ${ }^{6}$ Division of Infectious Diseases, University of Michigan, \\ Ann Arbor, MI \\ ${ }^{7}$ Division of Infectious Diseases, University of Miami, \\ Miami, FL \\ ${ }^{8}$ Division of Infectious Diseases, University of California, \\ San Francisco, CA \\ ${ }^{9}$ Division of Infectious Diseases, Department of \\ Medicine, Perelman School of Medicine of the University \\ of Pennsylvania, Philadelphia, PA \\ *Corresponding author: Marilyn E. Levi, \\ marilyn.levi@ucdenver.edu
}

In February 2013, the Organ Procurement and Transplantation Network mandated that transplant centers perform screening of living kidney donors prior to transplantation for Strongyloides, Trypanosoma cruzi and West Nile virus (WNV) infection if the donor is from an endemic area. However, specific guidelines for screening were not provided, such as the optimal testing modalities, timing of screening prior to donation and the appropriate selection of donors. In this regard, the American Society of Transplantation Infectious Diseases Community of Practice, together with disease-specific experts, has developed this viewpoint document to provide guidance for the testing of live donors for Strongyloides, T. cruzi and WNV infection, specifically identifying at-risk populations and testing algorithms, including advantages, limitations and interpretation of results.

Keywords: Clinical research/practice, donor evaluation, donor-derived infections, donors and donation, infectious disease

\begin{abstract}
Abbreviations: CDC, Centers for Disease Control and Prevention; EIA, enzyme-linked immunoassay; FDA, Food and Drug Administration; ID-NAT, individual donation-nucleic acid amplification test; IND, investigational new drug; MP-NAT, minipool-nucleic acid amplification test; MPX, multiplex; NAT, nucleic acid amplification test; OPTN, Organ Procurement and Transplantation Network; PCR, polymerase chain reaction; RT-PCR, reverse transcription-polymerase chain reaction; T. cruzi, Trypanosoma cruzi; WNV, West Nile virus
\end{abstract}

Received 05 November 2013, revised 24 December 2013 and accepted for publication 12 January 2014

\section{Introduction}

Strongyloides, Trypanosoma cruzi and West Nile virus (WNV) are important pathogens that have been transmitted via deceased organ donors. Given the potential for transmission to result from living donation, the Organ Procurement and Transplantation Network (OPTN) mandated, effective February 2013, that transplant centers must test for evidence of infection with Strongyloides, T. cruzi and WNV if the potential live donor is from an endemic area (1). However, the policy does not provide specific guidance regarding implementation, including appropriate selection of donors for testing, optimal testing modalities and timing. Therefore, the American Society of Transplantation Infectious Diseases Community of Practice, in conjunction with disease-specific experts, has developed this viewpoint to provide guidance related to testing of live donors for these infections with a focus on the identification of at-risk populations, advantages and limitations of specific testing algorithms, and interpretation of results.

\section{Strongyloides}

Infection with Strongyloides stercoralis occurs when the larvae penetrate the skin of persons walking in soil contaminated with feces and typically occurs in people from rural agricultural areas, especially if poor sanitation exists. Autoinfection is an important source of prolonged carriage and adult worms can live for up to 5 years, allowing for ongoing infection even when the donor is no longer living in the endemic area. Consequently, individuals may 


\section{Levi et al}

remain chronically infected and able to transmit infection throughout their lives via organ donation. Individuals infected with Strongyloides are often asymptomatic; symptomatic infection occurs more commonly in immunocompromised hosts. Manifestations may be variable and involve the gastrointestinal and/or pulmonary tracts, sepsis syndromes, gram-negative bloodstream infections, and/or meningitis (especially with gram-negative organisms). The most severe manifestation is hyperinfection syndrome (2).

The precise prevalence of chronic infection is unknown. The disease occurs throughout the world and infection rates are highest in tropical or subtropical regions, exceeding $80 \%$ in some locations. In the United States, rates as high as 3.8\% have been measured in Appalachia and southeastern states (3). The last community-based survey was conducted in 1982, and current rates are unknown.

\section{Which living donor candidates should be screened for Strongyloides?}

Strongyloidiasis typically occurs only in the setting of specific environmental exposures; thus, screening all potential live donors is not indicated. Screening is justified for the following potential organ donors:

- Persons who were born in or lived in tropical or subtropical countries where sanitation conditions are substandard. This includes candidates with prior military service in endemic areas. Strongyloidiasis has occurred in most countries with the exception of Canada, Japan and Northern Europe.

- Persons with unexplained eosinophilia and travel to endemic area.

- Those born in the United States who have significant exposure to soil in Appalachia or the southeastern United States.

- Persons reporting a prior history of Strongyloides infection.

\section{How should donor candidates be screened for Strongyloides?}

Strongyloides IgG antibody testing is readily available in many reference labs (Table 1). Currently, these ELISA assays (which correlate with antibody to filariform larvae) are not specifically approved by the Food and Drug Administration (FDA) for donor testing. Test sensitivities vary and false-negative results have occurred, including in early infection and immunocompromised hosts. Indirect immunofluorescence assays have improved sensitivity; however, they are generally only available through research laboratories. There is no standard commercially available confirmatory testing for antibody positive specimens; falsepositive tests are uncommon. Individuals with a history of treatment for Strongyloides infection may have persistent antibody; consequently, those donors should undergo further evaluation by an expert in infectious diseases. Serology is the preferred screening test for Strongyloides infection, as the sensitivity of stool testing is limited and multiple stool screening tests may be negative in asymptomatic chronic infection. Fecal examination for Strongyloides larvae may sometimes identify additional infected individuals who are newly infected and can be requested at the time of the initial evaluation. Because the methodology used to identify Strongyloides differs from that for routine ova and parasite examinations, it is important to specify the organism when ordering the test. Multiple stool specimens should be obtained to increase the yield; the optimal number is unknown but reports note that seven consecutive daily specimens may increase the sensitivity to nearly $100 \%$ (4). Given that transplant candidates may share similar epidemiological risk factors for Strongyloides infection, potential recipients with similar geographic exposures should also be considered for screening and treatment should be administered if found to be positive.

Eosinophilia is commonly seen in patients with active Strongyloides infection. Thus, those individuals with potential environmental exposures and unexplained eosinophilia should undergo serological testing and fecal examination for Strongyloides. However, since eosinophilia is not universally noted in patients with chronic strongyloidiasis, it should not be used as the only determinant for which individuals are screened with serologic testing. The optimal timing of live donor testing has not been established. However, unless the donor will resume residence in an environment where new exposures are likely, it is reasonable to test at the time of donor identification.

Table 1: Serological tests available for Strongyloides infection ${ }^{1}$

\begin{tabular}{lccc}
\hline Test name & Test format & Sample type & Available through \\
\hline Strongyloides IgG antibody & EIA & Serum & Focus Diagnostics, Inc. \\
Strongyloides antibody, IgG & EIA & Serum & ARUP Labs, Salt Lake City, UT \\
Strongyloides IgG antibody & EIA & Serum & Mayo Medical Laboratories \\
Strongyloides IgG antibody IVD-ELISA & EIA & Serum & IVD Research, Carlsbad, CA \\
Strongloides IgG antibody & EIA & Serum & Quest Diagnostics Nichols Institute \\
\hline
\end{tabular}

\footnotetext{
${ }^{1}$ Serological testing also available via CDC.
} 


\section{Can infected donors be considered for transplantation?}

Donor-derived strongyloidiasis has been rarely reported in the setting of deceased kidney donation, typically related to the use of donors from endemic areas (5). It has been suggested that the risk of donor-derived strongyloidiasis is enhanced due to predonation conditioning with high-dose corticosteroids. Consequently, it is unclear if live donors will pose the same risk for transmission as noted with deceased donors. Nevertheless, given the availability of effective treatment options for Strongyloides infection, infected individuals can be considered for live donation. Ideally, infected donors should be treated with a minimum of two doses of ivermectin prior to donation $(200 \mu \mathrm{g} / \mathrm{kg}$ orally daily on 2 consecutive days) (6). Because of the potential for persistence of migrating larvae and eggs in the tissues, some experts recommend repeating this treatment 2 weeks later to cover an autoinfection cycle. Following treatment, there is no need for follow-up laboratory testing of the donor prior to donation for confirmation of cure, unless re-exposure has occurred.

\section{How should the recipients of Strongyloides-positive donor organs be managed posttransplant?}

If the donor is treated prior to donation, no specific treatment or monitoring of the recipient is required as the likelihood of transmission is probably extremely low.

If the donor cannot be treated prior to donation or receives only a single course of treatment, then the recipient should be treated with the same regimen as outlined for the donor (considering two courses of two doses of ivermectin separated by 2 weeks as the most conservative approach) as soon as possible after the transplant has occurred (7). There are no significant drug interactions and the medication is typically well tolerated with no requirement for dose adjustment based on either renal or hepatic function. All recipients of organs from donors with Strongyloides infection should be monitored clinically; no additional serological or microbiological studies are indicated in the absence of symptoms. If recipients develop signs and symptoms consistent with Strongyloides infection or eosinophilia, expert consultation should be obtained. Serological diagnosis is unreliable in patients receiving immunosuppressive medications; therefore, appropriate samples (e.g. stool, respiratory samples) should be obtained for direct examination for Strongyloides larvae. Because eosinophilia is not always present, its absence cannot exclude the diagnosis. Recipients with posttransplant Strongyloides infection should be treated with ivermectin; the dose and duration may vary with the specific clinical syndrome and expert consultation should be solicited (7).

\section{Chagas Disease}

T. cruzi infection (the agent of Chagas disease) is most commonly transmitted through contact with infected triatomine "kissing" bugs, but transmission has also been reported through blood transfusion, organ transplantation and from mother to infant. Residents of poorly constructed housing where these insects reside are at greatest risk of acquiring infection. Endemic areas include many parts of Mexico and most of Central and South America (see Table 2). However, due to recent immigration it is estimated that more than 300000 T. cruzi infected people are living in the United States. In the United States, 32 organ transplant recipients from $14 \mathrm{~T}$. cruzi seropositive donors have been investigated: 2 of 15 (13\%) kidney recipients had donor-derived infection (8). A transmission rate of $18.7 \%$ was observed in a case series from Argentina of $T$. cruzi seropositive kidney donors and $T$. cruzi seronegative recipients (9). No live donor-derived T. cruzi infection has been reported in the United States but this has been described in Mexico and South America $(8,9)$. Clinical manifestations of donor-derived $T$. cruzi infection can include fever, malaise, anorexia, hepatosplenomegaly and acute myocarditis with a mean time to diagnosis of infection of 8 weeks (range 3-29 weeks) (8).

\section{Which living donor candidates should be screened for Chagas disease?}

T. cruzi can remain latent in humans for decades and be transmitted by organ donation with severe consequences to the recipient. Therefore, screening potentially infected living donors is appropriate. Individuals reporting only brief visits to endemic areas or residence confined to urban areas are considered lower risk for $T$. cruzi infection and may not need to be screened; however, these criteria have not been fully evaluated.

Table 2: Countries with endemic Chagas disease ${ }^{1,2}$

\begin{tabular}{l} 
Argentina \\
Belize \\
Bolivia \\
Brazil \\
Chile \\
Colombia \\
Costa Rica \\
Ecuador \\
El Salvador \\
French Guiana \\
Guatemala \\
Guyana \\
Honduras \\
Mexico \\
Nicaragua \\
Panama \\
Suriname \\
Paraguay \\
Peru \\
Uruguay \\
Venezuela \\
\hline Adapted from: http://www.cdc.gov/parasites/cme/chagas/course. \\
html. \\
${ }^{1}$ See (1). \\
${ }^{2}$ A map of endemic areas for Trypanosoma cruzi infection is \\
available on the World Health Organization website. \\
\end{tabular}




\section{Levi et al}

Donors who should be screened include:

- Those who were born in or lived in an endemic region in Mexico, Central or South America (see Table 2).

- Children of women who lived in endemic regions and whose T. cruzi infection status is positive or unknown.

- Persons who have received a blood transfusion in endemic regions.

- Persons reporting a prior history of Chagas disease.

\section{How should at-risk donor candidates be tested for Chagas disease?}

At the time of evaluation, potential living donors should be tested for Chagas disease using serologic methods to detect antibody (Table 3). Serology is preferred because individuals with indeterminate chronic phase $T$. cruzi infection have extremely low-level parasitemia, and therefore polymerase chain reaction (PCR), smears and cultures have low sensitivity. Once infected, antibody levels are usually detectable within 1 month and persist throughout life.

Three FDA-cleared diagnostic tests for Chagas disease are available for screening in the United States (Table 3). The Ortho T. cruzi enzyme-linked immunoassay (EIA) test system is used in blood donor screening and has been approved for diagnostic testing as well but is not available in individual test kits; coordination with blood donor testing centers would be required to utilize this test. The Hemagen Chagas' Kit (Hemagen Diagnostics, Inc., Columbia, MD) and the Chagatest EIA Recombinante v. 3.0 (Wiener Laboratories, Rosario, Argentina) are individual test kits for patient testing and could be used to diagnose infection in potential donors. Potential donors with any of the noted epidemiologic risk factors for Chagas should undergo one of the three available tests; notably performance does differ among the available tests. If the initial screening test result is positive, a second test utilizing a different antigen or technique is recommended for serologic confirmation. There is no gold standard for testing for $T$. cruzi and discordant test results are an indication for further testing. All live donors should be notified of their test results. Consultation with infectious diseases experts is recommended for evaluation of potential donors whose initial screening test is positive for further testing recommendations, interpretation of test results and assessment of the need for donor treatment.

\section{Can infected donors be considered for transplantation?}

Available data indicate that the risk of transmission of T. cruzi from a deceased kidney donor to an uninfected organ recipient is $13-18 \%(8,10)$. The risk of transmission from live kidney donors is unknown. Posttransplant monitoring can be performed to identify subclinical infection and treatment can abort the development of clinical disease following infection. Therefore, the authors agree with recent guidelines considering kidney donation from infected donors on an individual basis with consent of the recipient (10). Potential recipients meeting criteria for $T$. cruzi screening should also be tested regardless of the donor's $T$. cruzi status. It is possible that many potential

Table 3: Serological tests available for T. cruzi infection ${ }^{1}$

\begin{tabular}{|c|c|c|c|c|}
\hline Test name, manufacturer & Target antigen & Test format & Sample type & FDA-cleared/approved use \\
\hline $\begin{array}{l}\text { Abbott Prism Chagas (T. cruzi } \\
\text { [E. coli, recombinant] } \\
\text { antigen), }{ }^{2} \text { Abbot Laboratories, } \\
\text { Abbott Park, IL }\end{array}$ & Recombinant antigens & ChLIA & Serum/plasma & Donor screening \\
\hline $\begin{array}{l}\text { ORTHO T. cruzi ELISA Test } \\
\text { System, }{ }^{3} \text { Ortho-Clinical } \\
\text { Diagnostics, Inc., Raritan, NJ }\end{array}$ & Whole cell lysate & EIA & Serum/plasma & $\begin{array}{l}\text { Donor screening, individual } \\
\text { diagnosis }\end{array}$ \\
\hline $\begin{array}{c}\text { Chagatest ELISA recombinant } \\
\text { v.3.0, }{ }^{3} \text { Wiener Laboratories } \\
\text { S.A.I.C., Rosario, Argentina }\end{array}$ & $\begin{array}{l}\text { Recombinant } \\
\text { epimastigote and } \\
\text { trypomastigote } \\
\text { proteins }\end{array}$ & EIA & Serum/plasma & $\begin{array}{l}\text { Diagnosis, NOT donor } \\
\text { screening test }\end{array}$ \\
\hline $\begin{array}{l}\text { Hemagen Chagas' Kit, } \\
\text { Hemagen Diagnostics, Inc., } \\
\text { Columbia, MD }\end{array}$ & $\begin{array}{l}\text { Purified antigens from } \\
\text { cultured } T . \text { cruzi }\end{array}$ & EIA & Serum & $\begin{array}{l}\text { Diagnosis, NOT donor } \\
\text { screening test }\end{array}$ \\
\hline $\begin{array}{l}\text { Abbott ESA Chagas Assay, } \\
\text { Abbott Laboratories, Abbott } \\
\text { Park, IL }\end{array}$ & $\begin{array}{l}4 \text { T. cruzi recombinant } \\
\text { antigens (FP10, FP6, } \\
\text { FP3, TCF) }\end{array}$ & $\begin{array}{l}\text { Enzyme } \\
\text { Strip Assay }\end{array}$ & Serum/plasma & $\begin{array}{l}\text { Supplemental test in donors } \\
\text { who test positive with } \\
\text { first-line assays, not } \\
\text { approved for individual } \\
\text { diagnosis }\end{array}$ \\
\hline
\end{tabular}

Adapted from http://www.fda.gov/BiologicsBloodVaccines/BloodBloodProducts/ApprovedProducts/LicenseProducts.

${ }^{1}$ Serological testing also available via CDC.

${ }^{2}$ This test may only be available through local blood bank.

${ }^{3}$ Preferred tests for initial donor screening. 
living donors share risk factors with their designated recipients; the risk of symptomatic disease when both donor and recipient are $T$. cruzi positive is unknown. Regardless, chronic recipient infection should be identified pretransplant to direct monitoring for reactivation disease after immunosuppression.

If transplantation from an infected donor is planned, given the complexity of posttransplant management, the following issues should be considered:

- Recipients should receive specific information regarding:

o The risk of transmission and the limited data regarding this risk, especially pertaining to live donors.

o The posttransplant monitoring process.

o The potential toxicities associated with treatment for Chagas disease.

o The need for participation in close monitoring of therapeutic interventions in the event of infection, since the medications available for treatment are not FDA approved and are generally only provided through specific protocols.

- Specific plans for posttransplant monitoring must be in place at the time of transplantation. It is imperative to consider the recipient's access to testing and monitoring as geographic concerns may impact the ability to follow the patient closely.

\section{How should the recipients of $\mathrm{T}$. cruzi positive donor organs be managed posttransplant?}

Following transplant, monitoring of recipients of kidneys from $T$. cruzi positive organ donors should be coordinated by local infectious disease experts and incorporate testing at a reference lab (such as the Centers for Disease Control and Prevention [CDC]). Serologic conversion may not occur due to posttransplant immunosuppressive therapy. Monitoring can be accomplished by PCR testing of blood for T. cruzi DNA and review of peripheral blood for parasitemia weekly for 2 months posttransplant, every 2 weeks for the third month, then monthly afterward for a period to be determined by the specific clinical scenario (10). An assessment of the organ recipient's net state of immunosuppression should be made in the first months posttransplant, and the monitoring interval adjusted accordingly. PCR testing (currently available only at $\mathrm{CDC}$ ) is more sensitive than direct parasitologic diagnosis, and may be positive days or weeks prior to the appearance of $T$. cruzi trypomastigotes in the blood (10). Indirect methods of parasite diagnosis such as hemoculture may require weeks to several months to obtain results. Additional testing is recommended in the setting of intensified immunosuppression, unexplained febrile illness or infection symptoms, or episodes of suspected graft rejection. The likelihood of late reactivation of donor-derived infection is unknown.

Routine prophylaxis of the recipient of a $T$. cruzi positive donor organ is not recommended (10-12). Treatment with both benznidazole and nifurtimox is frequently complicated by significant side effects and there is no clear treatment end point to indicate when infection is definitively cured. Consequently, even recipients of donors who had been previously treated need to be monitored for posttransplant parasitemia. Because neither benznidazole nor nifurtimox is FDA approved or commercially available in the United States, these medications must be obtained for patients with confirmed $T$. cruzi infection through an investigational new drug (IND) protocol directly from CDC or independently. For this reason, and because of the expertise of CDC laboratories in expedited testing of high-risk organ recipients, early notification of CDC at the time of transplant is advised. Ideally treatment should be initiated in those with increasing reactivity in serial PCR as seropositivity occurs later $(8,13)$. In the United States, consultation about known or suspected $T$. cruzi infections, confirmatory testing, monitoring and treatment of transplant recipients should be directed to the Division of Parasitic Diseases and Malaria, CDC (Tel: 404-718-4745, parasites@cdc.gov, or CDC Emergency Operations Center 770-488-7100). Treatment of donor-derived infection requires close monitoring for adverse effects, and the involvement of an infectious diseases consultant is recommended.

\section{West Nile Virus}

WNV is a flavivirus that is transmitted by mosquitoes in an enzootic cycle with birds. In the United States, WNV was first noted in 1999 in the New York City area and has since become endemic in widespread regions of the United States (14). WNV infection is associated with a range of clinical symptoms ranging from asymptomatic infection to neuroinvasive disease. In the immunocompetent population, neuroinvasive disease occurs in 1 in 150 infected individuals and is manifested by altered mental status, meningitis, encephalitis, flaccid paralysis and occasionally death; these complications are estimated to occur in 1 in 40 transplant recipients infected by mosquito bites (15). Transmission has also occurred via blood and deceased organ donation with an incidence of neuroinvasive disease ranging between $50 \%$ and $75 \%$ (16-18). Since 2002, donorderived transmission events associated with at least nine donors infecting solid organ transplant recipients have been reported (17-23). No transmissions have been reported via live donor transplants thus far.

\section{Which living donors should be screened for WNV?}

Because WNV is seasonal throughout the United States, year round screening of potential living donors is unlikely to be cost-effective and may result in increased false-positive results associated with testing low prevalence populations (24). As false-positive results may result in potential organ loss or unnecessary delays in transplantation, timing of testing is critical. Blood banks in the United States screen year-round for WNV using nucleic acid amplification testing (NAT) which identifies the presence of RNA. Due to 


\section{Levi et al}

limitations in reagent availability, personnel and other logistical issues, blood donors are tested in minipools (minipool-nucleic acid amplification test [MP-NAT]). Once one or more minipools is positive by NAT, the blood bank begins screening individual samples (individual donationnucleic acid amplification test [ID-NAT]) (25).

One potential strategy for determining when to begin testing potential living donors for WNV would be to follow when regional blood banks start performing ID-NAT screening. This will allow for recognition of the onset of WNV in the donor's region of residence, travel or work locations (26). This approach requires coordination with blood banks. Further, blood banks vary in their criteria from switching between minipool and individual NAT; there is no national standard for blood banks on this issue. Consequently, while basing testing of living donors on regional blood banking WNV results may be cost-effective and associated with the highest positive predictive value for positive NATs, this approach may be impractical for some transplant centers. Knowledge of epidemiologic data such as the number of clinical cases or presence of positive bird or mosquito pools in the donor's areas of potential exposures as reported by local health departments may be useful to transplant centers assessing WNV risk. It should be noted that nonhuman surveillance activities are variable between jurisdictions. Another potential strategy would be the development of a central notification system that could alert transplant centers regarding regional WNV activity.

A second option is to test during a defined period of time that reflects the peak of WNV infection in most of the United States (typically May 1 to November 1). This may be simpler for centers to adopt. In addition, this reduces the likelihood of communication error between laboratories and blood banks. The major disadvantage with this method is that potential donors will be tested despite the absence of circulating WNV in their locales, thereby increasing the likelihood of false-positive test results.

Any potential donor with a recent febrile illness should be screened by local infectious diseases expertise prior to donation. This screening may include West Nile testing as appropriate.

During mosquito season, prospective live donors should be counseled to use personal protective measures against mosquito bites such as insect repellents and avoidance of outside activities between dusk to dawn. These practices are meant to mitigate the risk of acquiring WNV between diagnostic testing and organ donation.

\section{How should live donors be tested?}

For laboratory screening, live donors should be screened by WNV NAT within 7-14 days of donation. There are currently two FDA-licensed donor screening NAT assays utilized by screening laboratories to detect the presence of infectious WNV virus (Table 4). The Procleix ${ }^{\circledR}$ WNV Assay (Gen-probe; Novartis Diagnostics, Basel, Switzerland) is based on transcription-mediated amplification, a NAT, which tests up to 16 specimens in the MP-NAT with a specificity of $99.95 \%$ and ID-NAT specificity of $99.89 \%(27,28)$. The Cobas TaqScreen MPX test (Roche Molecular Diagnostics, Branchburg, NJ) utilizes reverse transcription PCR (RT$\mathrm{PCR}$ ) to test up to six specimens with an MP-NAT specificity of $100 \%$ and ID-NAT specificity of $99.98 \%$ $(29,30)$ (Table 5). Interpretation of the results can be based on the positive predictive value in each case, such as the prevalence of WNV in the community where the donor resides or has traveled.

The use of serologic testing offers an additional potential strategy to screen potential living donors for WNV but poses significant limitations in its performance and interpretation. WNV antibody testing has been done to establish the presence of past infection. This testing involves (1) IgM, which develops within 2-3 days of resolution of viremia, but may persist for $>500$ days (31), and (2) $\lg$, which is identified within 2-3 days of $\lg M$ production and persists for at least 5 years $(32,33)$. It is important to note that serologic tests against WNV are not FDA licensed for the screening of donors. However, a potential role for $\operatorname{lgM}$ antibody testing is raised by the fact that two of the nine deceased organ donors who

Table 4: Performance summary of FDA-cleared WNV antibody diagnostic tests

\begin{tabular}{|c|c|c|}
\hline Assay & $\begin{array}{c}\text { Aggregate range of } \\
\text { specificity \% (range } 95 \% \mathrm{Cl} \text { ) }\end{array}$ & $\begin{array}{l}\text { Aggregate range of clinical } \\
\text { sensitivity \% (range 95\% Cl) }\end{array}$ \\
\hline Focus Technologies WNV IgM Capture ELISA ${ }^{1}$ (39-41) & $97.1-100(92.7-100)$ & $93.2-100(81.3-100)$ \\
\hline Focus Technologies WNV IgM Capture ELISA ${ }^{1}$ (42) & $68-99.2^{2}$ & 99.3 \\
\hline Focus Technologies WNV ELISA IgG $(40,41,43)$ & $90-98.8(86-100)^{2}$ & $36-98.8(25.2-99.9)^{2}$ \\
\hline Focus Technologies WNV ELISA IgG (42) & $41-97.4^{2}$ & 97.6 \\
\hline InBios WNV Detect IgM ELISA (44) & $98.4-100(94.3-100)$ & $96.2-99.4(87.0-99.9)$ \\
\hline PANBIO WNV IgM Capture ELISA ${ }^{3}(41,45)$ & $85.5-98.4(75-100)$ & $76.7-100(69-100)$ \\
\hline PANBIO WNV IgG Indirect ELISA ${ }^{3}(41,46)$ & $88.1-92.6(87.6-97.6)$ & $76.3-99.3(59.8-100)$ \\
\hline Spectral Diagnostics WNV IgM STATus Test (47) & 96-99.4 (82.8-99.9) & $80-100(59.3-100)$ \\
\hline
\end{tabular}

\footnotetext{
${ }^{1}$ Solely performance with background subtraction method reported.

${ }^{2}$ Excluded indeterminate samples in analysis.

${ }^{3}$ Not commercially available in the United States outside of research use.
} 
Live Kidney Donor Screening for Endemic Infections

Table 5: Performance summary of FDA-approved donor screening WNV NAT assays

\begin{tabular}{lccc}
\hline Assay & $\begin{array}{c}\text { Aggregate range } \\
\text { of specificity \% } \\
\text { (range 95\% Cl) }\end{array}$ & $\begin{array}{c}\text { Aggregate range } \\
\text { of clinical sensitivity \% } \\
\text { (range 95\% Cl) }\end{array}$ & $\begin{array}{c}\text { Aggregate 95\% } \\
\text { limit of detection for } \\
\text { WNV RNA (95\% Cl) }\end{array}$ \\
\hline $\begin{array}{l}\text { Gen-Probe PROCLEIX } \\
\text { WNV Assay (28,48,49) }\end{array}$ & $99.89-100(99.89-100)$ & $91.6-100(86.9-100)$ & $8.2-15 \mathrm{copies} / \mathrm{mL}(5.5-27.3)$ \\
$\begin{array}{l}\text { Roche (14) Cobas TaqScreen } \\
\text { WNV Test }(29,49,50)\end{array}$ & $99.986-100(99.950-100)$ & $100(98.8-100)$ & $\begin{array}{c}40.3-125 \mathrm{copies} / \mathrm{mL} \text { or 0.8 plaque } \\
\text { forming units }{ }^{1}(17)\end{array}$ \\
\hline
\end{tabular}

${ }^{1}$ Reference cites unpublished CDC data.

transmitted WNV and underwent screening prior to organ procurement had negative RT-PCR assays but positive WNV IgM and IgG antibodies (20-22,26). The failure of NAT in one case was attributed to the decreased sensitivity of the TaqMan RT-PCR (17). However, the second NAT failure in a 2011 transmission case in California was reportedly RT-PCR negative in serum and IgM positive as well (19). Another major caveat of WNV antibody testing is the crossreactivity with other flaviviridae such as Dengue, Japanese Encephalitis, St. Louis Encephalitis and Yellow fever among others. Therefore, individuals who have had any of these infections or vaccinations against flaviviridae may have false-positive WNV antibody testing. Confirmatory testing via plaque reduction neutralization assay may be obtained through the $C D C$, although the results are generally not available in a timely fashion to assist in donor screening depending on the urgency of transplant.

\section{Interpreting WNV testing}

A positive WNV NAT should lead to further evaluation of the live donor and donation should be deferred until repeat testing confirms resolution of viremia and infectivity. For blood donors, the FDA recommends deferring donation for 120 days in those with confirmed WNV infection $(32,34)$.

However, further management of a positive NAT test in live donors is unclear because of limited data. One strategy for donor testing is provided in Figure 1. It is reasonable to repeat NAT testing in this situation; the time to repeat and number of repeat samples may vary depending on the

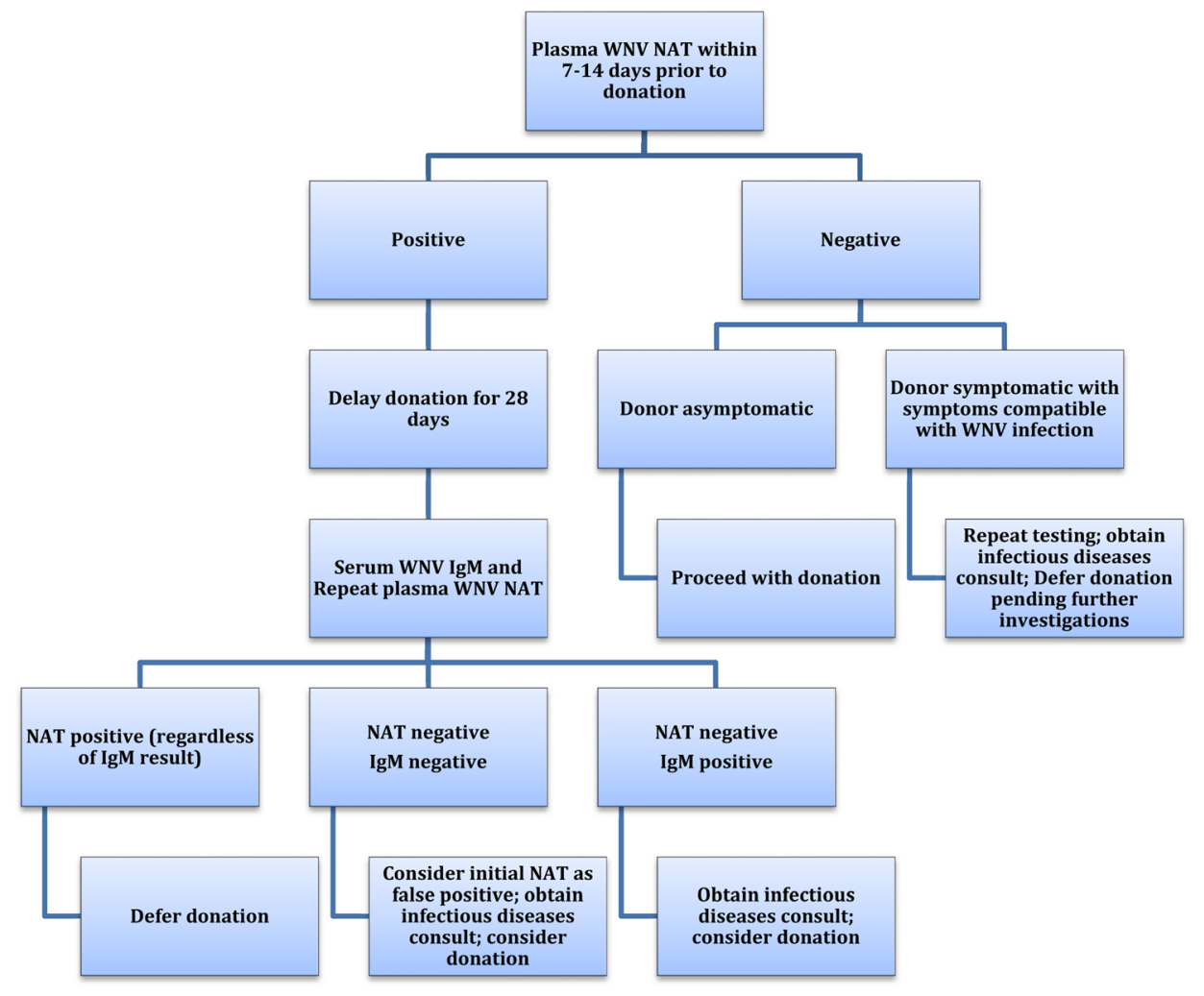

Figure 1: Strategy for testing live donors for West Nile virus. 


\section{Levi et al}

availability of the donor and turnaround time of testing. It is unknown whether a negative NAT on repeat testing confirms that the initial test was a false-positive result. Failure to seroconvert at 28 days would lend support that the initial NAT was false positive. Accordingly, a negative repeat NAT and WNV IgM and IgG at 28 days suggests that the original result was a false positive. Thus, transplantation of the kidney from the donor could be considered at that time. In contrast, a positive WNV IgM at 28 days in a donor who previously had positive WNV NAT strongly suggests that the donor had been infected, regardless of the repeat NAT result; however, making clinical decisions based upon a positive IgM result in this setting is not clear. While a negative NAT and positive IgM at 28 days likely indicate clearance of viremia and the development of protective antibodies, the duration of WNV persistence in organs is unknown. Therefore, the appropriate period to wait in a donor with confirmed WNV infection is also unknown. Clinical history together with seasonal and geographic considerations may further assist in the risk assessment for WNV transmission.

\section{Posttransplant management of recipients of a WNV-positive organ donor}

At this time, there is no effective treatment for WNV. Consequently, donors with active WNV should be deferred. In the event of inadvertent transplantation from a WNV infected donor, immunosuppression should be minimized and hyperimmune globulin can be considered (35). Hyperimmune globulin may be available on a compassionate use basis from Omrix and would likely require an IND; however, the presence of antibody to WNV in US-derived immune globulin has been reported (19,36-38). Recipients may be monitored with serial NAT testing to determine the presence of infection. In the event of a positive NAT result, consultation with local infectious diseases experts is recommended, as well as reporting to transplant centers and public health authorities.

\section{Conclusions}

Identifying live donors with potentially transmissible infections should enhance the safety of transplantation, a key objective of the OPTN in mandating testing for WNV, T. cruzi and Strongyloides in this setting. Given that these are uncommon infections in the United States, typically occurring in individuals with specific epidemiologic risk factors, broad testing of all donors throughout the year and in all locales may not be cost-efficient and, in some cases, may unnecessarily eliminate donors or delay transplantation due to false-positive results. In all cases, live donors should also be notified of their positive results. Identifying at-risk donors for targeted testing is critical for efficient utilization of live donors. Banking serum may be a useful tool for confirming donor-derived infection with Strongyloides, T. cruzi and WNV.

\section{Acknowledgments}

We thank Dr. Susan Stramer of the American Red Cross, Drs. Matthew Kuehnert, Susan Montgomery, Erin S. Staples and Ingrid Rabe of the CDC and Dr. Melissa Greenwald of the FDA for their invaluable contributions.

\section{Disclosure}

The authors of this manuscript have no conflicts of interest to disclose as described by the American Journal of Transplantation.

\section{References}

1. Network OPaT. Living Donation 2013 (updated May 31, 2013). Available at: http://optn.transplant.hrsa.gov/PoliciesandBylaws2/ policies/pdfs/policy_172.pdf. Accessed July 16, 2013.

2. Roxby AC, Gottlieb GS, Limaye AP. Strongyloidiasis in transplant patients. Clin Infect Dis 2009; 49: 1411-1423.

3. Starr MC, Montgomery SP. Soil-transmitted Helminthiasis in the United States: A systematic review-1940-2010. Am J Trop Med Hyg 2011; 85: 680-684.

4. Siddiqui AA, Berk SL. Diagnosis of Strongyloides stercoralis infection. Clin Infect Dis 2001; 33: 1040-1047.

5. Abanyie FBE, Montgomery S, Kuehnert M, Hocevar S, Chin-Hong P. Donor-derived Strongyloidiasis in transplant recipients-United States 2009-2012. Am J Transplant 2013; 13 (Suppl 5): 139.

6. Igual-Adell R, Oltra-Alcaraz C, Soler-Company E, Sanchez-Sanchez P, Matogo-Oyana J, Rodriguez-Calabuig D. Efficacy and safety of ivermectin and thiabendazole in the treatment of Strongyloidiasis. Expert Opin Pharmacother 2004; 5: 2615-2619.

7. Schwartz BS, Mawhorter SD. Parasitic infections in solid organ transplantation. Am J Transplant 2013; 13: 280-303.

8. Huprikar S, Bosserman E, Patel G, et al. Donor-derived Trypanosoma cruzi infection in solid organ recipients in the United States, 2001-2011. Am J Transplant 2013; 13: 2418-2425.

9. Riarte A, Luna C, Sabatiello R, et al. Chagas' disease in patients with kidney transplants: 7 Years of experience 1989-1996. Clin Infect Dis 1999; 29: 561-567.

10. Chin-Hong PV, Schwartz BS, Bern C, et al. Screening and treatment of Chagas disease in organ transplant recipients in the United States: Recommendations from the chagas in transplant working group. Am J Transplant 2011; 11: 672-680.

11. Bern C. Antitrypanosomal therapy for chronic Chagas' disease. N Engl J Med 2011; 364: 2527-2534.

12. Kransdorf EP, Czer LS, Luthringer DJ, et al. Heart transplantation for chagas cardiomyopathy in the United States. Am J Transplant 2013; 13: 3262-3268.

13. Qvarnstrom Y, Schijman AG, Veron V, Aznar C, Steurer F, da Silva AJ. Sensitive and specific detection of Trypanosoma cruzi DNA in clinical specimens using a multi-target real-time PCR approach. PLoS Negl Trop Dis 2012; 6: e1689.

14. Hayes EB, Komar N, Nasci RS, Montgomery SP, O'Leary DR, Campbell GL. Epidemiology and transmission dynamics of West Nile virus disease. Emerg Infect Dis 2005; 11: 1167-1173.

15. Kumar D, Prasad GV, Zaltzman J, Levy GA, Humar A. Communityacquired West Nile virus infection in solid-organ transplant recipients. Transplantation 2004; 77: 399-402.

16. Singh N, Levi ME. Arenavirus and West Nile virus in solid organ transplantation. Am J Transplant 2013; 13: 361-371. 


\section{Live Kidney Donor Screening for Endemic Infections}

17. Iwamoto M, Jernigan DB, Guasch A, et al. Transmission of West Nile virus from an organ donor to four transplant recipients. New Engl J Med 2003; 348: 2196-2203.

18. Pealer LN, Marfin AA, Petersen LR, et al. Transmission of West Nile virus through blood transfusion in the United States in 2002. New Engl J Med 2003; 349: 1236-1245.

19. Rhee C, Eaton EF, Concepcion W, Blackburn BG. West Nile virus encephalitis acquired via liver transplantation and clinical response to intravenous immunoglobulin: Case report and review of the literature. Transpl Infect Dis 2011; 13: 312-317.

20. Planitzer CB, Modrof J, Kreil TR. West Nile virus neutralization by US plasma-derived immunoglobulin products. MMWR Morb Mortal Wkly Rep 2005; 54: 1021-1023.

21. Blau DM, Rabe IB, Bhatnagar J, et al. West Nile virus RNA in tissues from donor associated with transmission to organ transplant recipients. Emerg Infect Dis 2013; 19: 1518-1520.

22. Costa AN, Capobianchi MR, Ippolito G, et al. West Nile virus: The Italian national transplant network reaction to an alert in the northeastern region, Italy 2011. Euro Surveill 2011; 16: e19-e21.

23. Inojosa WO, Scotton PG, Fuser $R$, et al. West Nile virus transmission through organ transplantation in north-eastern Italy: A case report and implications for pre-procurement screening. Infection 2012; 40: 557-562.

24. Zou S, Foster GA, Dodd RY, Petersen LR, Stramer SL. West Nile fever characteristics among viremic persons identified through blood donor screening. J Infect Dis 2010; 202: 1354-1361.

25. Busch MP, Caglioti S, Robertson EF, et al. Screening the blood supply for West Nile virus RNA by nucleic acid amplification testing. N Engl J Med 2005; 353: 460-467.

26. Nett RJ, Kuehnert MJ, Ison MG, Orlowski JP, Fischer M, Staples JE. Current practices and evaluation of screening solid organ donors for West Nile virus. Transpl Infect Dis 2012; 14: 268-277.

27. Insert NDP: Procleix ${ }^{\circledR}$ WNVAssay (April 20, 2013). Available at: http://www.fda.gov/downloads/BiologicsBloodVaccines/ BloodBloodProducts/ApprovedProducts/LicensedProductsBLAs/ BloodDonorScreening/InfectiousDisease/ucm090247.pdf. Accessed December 14, 2013.

28. Linnen JM, Deras ML, Cline J, et al. Performance evaluation of the PROCLEIX West Nile virus assay on semi-automated and automated systems. J Med Virol 2007; 79: 1422-1430.

29. Pai A, Kleinman S, Malhotra K, Lee-Haynes L, Pietrelli L, Saldanha J. Performance characteristics of the Food and Drug Administration-licensed Roche Cobas TaqScreen West Nile virus assay. Transfusion 2008; 48: 2184-2189.

30. Insert: RMSIP. cobas ${ }^{\mathbb{R}}$ TaqScreen West Nile Virus Test for use on the cobas s 201 system.

31. Roehrig JT, Nash D, Maldin B, et al. Persistence of virus-reactive serum immunoglobulin $m$ antibody in confirmed West Nile virus encephalitis cases. Emerg Infect Dis 2003; 9: 376-379.

32. Busch MP, Kleinman SH, Tobler $L$, et al. Virus and antibody dynamics in acute West Nile virus infection. J Infect Dis 2008; 198: 984-993.

33. Carson PJ, Prince HE, Biggerstaff BJ, Lanciotti R, Tobler LH, Busch $M$. Characteristics of antibody responses in West Nile virus seropositive blood donors. J Clin Microbiol 2014; 52: 57-60.

34. Center for Biologics Evaluation and Research FDA. Guidance for industry: Assessing donor suitability and blood product safety in cases of known or suspected West Nile virus infection. Available at: http://www.fda.gov/biologicsbloodvaccines/guidancecomplianceregulatoryinformation/guidances/blood/ucm074111. htm. Accessed June 16, 2013

35. Ben-Nathan D, Gershoni-Yahalom O, Samina I, et al. Using high titer West Nile intravenous immunoglobulin from selected Israeli donors for treatment of West Nile virus infection. BMC Infect Dis 2009; 9: 18.

36. Planitzer CB, Modrof J, Kreil TR. West Nile virus neutralization by US plasma-derived immunoglobulin products. J Infect Dis 2007; 196: 435-440.

37. Planitzer CB, Modrof J, Yu MY, Kreil TR. West Nile virus infection in plasma of blood and plasma donors United States. Emerg Infect Dis 2009; 15: 1668-1670.

38. Saquib R, Randall H, Chandrakantan A, Spak CW, Barri YM. West Nile virus encephalitis in a renal transplant recipient: The role of intravenous immunoglobulin. Am J Kidney Dis 2008; 52: e19-e21.

39. Focus Diagnostics, Package insert: West Nile Virus IgM Capture DxSelect $^{\mathrm{TM}}$ (English) Enzyme-linked Immunosorbent Assay (ELISA) Product Code EL 0300M. (April 18, 2013); Rev. M. Available at: http://www.focusdx.com/pdfs/pi/US/EL0300M.pdf. Accessed February 6, 2014.

40. Malan AK, Stipanovich PJ, Martins TB, Hill HR, Litwin CM. Detection of $\operatorname{lgG}$ and $\operatorname{lgM}$ to West Nile virus. Development of an immunofluorescence assay. Am J Clin Pathol 2003; 119: 508-515.

41. Malan AK, Martins TB, Hill HR, Litwin CM. Evaluations of commercial West Nile virus immunoglobulin G (lgG) and $\operatorname{lgM}$ enzyme immunoassays show the value of continuous validation. J Clin Microbiol 2004; 42: 727-733.

42. Hogrefe WR, Moore R, Lape-Nixon M, Wagner M, Prince HE. Performance of immunoglobulin G (IgG) and IgM enzyme-linked immunosorbent assays using a West Nile virus recombinant antigen (preM/E) for detection of West Nile virus- and other flavivirus-specific antibodies. J Clin Microbiol 2004; 42: 46414648.

43. Focus Diagnostics, Package insert: West Nile Virus IgG DxSelect ${ }^{\mathrm{TM}}$ Enzyme-linked Immunosorbent Assay (ELISA) Product Code EL 0300G-5 (April 18, 2013); Rev. F. Available at: http:// www.focusdx.com/pdfs/pi/US/EL0300G-5.pdf. Accessed February 6, 2014.

44. InBios International Inc. Package insert: West Nile Detect ${ }^{\mathrm{TM}}$ IgM Capture ELISA for In Vitro Diagnostic Use. 2012 (April 18, 2013). Available at: http://www.inbios.com/cms/file/900015-05\%20\% 20IVD \% 20West \% 20Nile \% 20Detect\% 20IgM \% 20Capture \% 20ELISA\%20Human\%20Insert.pdf. Accessed February 6, 2014.

45. Panbio diagnostics. PANBIO WNV IgM Capture ELISA Package insert (April 18, 2013).

46. Panbio diagnostics. PANBIO WNV IgG Capture ELISA Package insert. (April 18, 2013).

47. Spectral Diagnostics, Inc. 510 (k) Summary of safety and effectiveness: Spectral West Nile IgM STATus ${ }^{\text {TM }}$ Test (June 9, 2013). Available at: http://www.accessdata.fda.gov/cdrh_docs/ pdf5/k052519.pdf. Accessed February 6, 2014.

48. Novartis Diagnostics, Package insert: Procleix ${ }^{\circledR}$ WNVAssay (April 20, 2013). Available at: http://www.fda.gov/downloads/ BiologicsBloodVaccines/BloodBloodProducts/ApprovedProducts/ LicensedProductsBLAs/BloodDonorScreening/InfectiousDisease/ ucm090247.pdf. Accessed February 6, 2014.

49. Busch MP, Tobler LH, Saldanha J, et al. Analytical and clinical sensitivity of West Nile virus RNA screening and supplemental assays available in 2003. Transfusion 2005; 45: 492-499.

50. Roche Molecular Systems Inc. Package insert: cobas ${ }^{\mathbb{R}}$ TaqScreen West Nile Virus Test for use on the cobas s 201 system (April 20, 2013). Available at: http://www.fda.gov/downloads/Biologics BloodVaccines/BloodBloodProducts/ApprovedProducts/Licensed ProductsBLAs/BloodDonorScreening/InfectiousDisease/UCM091938. pdf. Accessed February 6, 2014 